\title{
Gas1 extends the range of Hedgehog action by facilitating its signaling
}

\author{
David C. Martinelli ${ }^{1,2}$ and Chen-Ming Fan ${ }^{1,3}$ \\ ${ }^{1}$ Department of Embryology, Carnegie Institution of Washington, Baltimore, Maryland 21218, USA; ${ }^{2}$ Department of Biology, \\ Johns Hopkins University, Baltimore, Maryland 21218, USA
}

\begin{abstract}
Cellular signaling initiated by Hedgehog binding to Patched1 has profound importance in mammalian embryogenesis, genetic disease, and cancer. Hedgehog acts as a morphogen to specify distinctive cell fates using different concentration thresholds, but our knowledge of how the concentration gradient is interpreted into the activity gradient is incomplete. The membrane protein Growth Arrest-Specific Gene 1 (GAS1) was thought to be a negative regulator of the Hedgehog concentration gradient. Here, we report unexpected genetic evidence that Gas1 positively regulates Hedgehog signaling in multiple developmental contexts, an effect particularly noticeable at regions where Hedgehog acts at low concentration. Using a combination of in vitro cell culture and in ovo electroporation assays, we demonstrate that GAS1 acts cooperatively with Patched1 for Hedgehog binding and enhances signaling activity in a cell-autonomous manner. Our data support a model in which GAS1 helps transform the Hedgehog protein gradient into the observed activity gradient. We propose that Gas1 is an evolutionarily novel, vertebrate-specific Hedgehog pathway regulator.
\end{abstract}

[Keywords: Gas1; Hedgehog; signaling; patterning; development; gradient]

Supplemental material is available at http://www.genesdev.org.

Received February 26, 2007; revised version accepted March 26, 2007.

The Hedgehog pathway features a cholesterol and palmitate modified, 19-kDa secreted Hedgehog protein (Porter et al. 1996; Pepinsky et al. 1998). In mammals, Indian Hedgehog (Ihh) and Sonic Hedgehog (Shh) encode two proteins responsible for all early embryonic Hedgehog function. "HH" will be used here to refer to properties common to both. They elicit pathway activation primarily through binding to the Patched1 (PTC1) protein, which, in turn, allows the Smoothened (SMO) protein to initiate a cascade of events leading to activity modulation of the GLI transcription factor family and regulation of downstream genes (Briscoe and Ericson 1999). Although the majority of $\mathrm{HH}$ protein is believed to be membrane bound, limiting it to local signaling, a small fraction can become soluble and diffuse to long distances (Zeng et al. 2001). The concentration gradient of the diffusible $\mathrm{HH}$ is transformed into graded signaling strengths in responding cells to specify them to an array of cell fates. To achieve a defined pattern of cell types within the target field, the contour of the gradient is finely tuned by HH-binding proteins such as PTC1. Ptc1 is directly up-regulated by $\mathrm{HH}$, thus providing a negative feedback loop to limit the range of diffusion by presenting additional binding sites for $\mathrm{HH}$ /Chen and Struhl

${ }^{3}$ Corresponding author.

E-MAIL fan@ciwemb.edu; FAX (410) 243-6311.

Article is online at http://www.genesdev.org/cgi/doi/10.1101/gad.1546307.
1996). The feedback loop predicts a sequestration of $\mathrm{HH}$ near its source, creating a steep gradient (Saha and Schaffer 2006). This causes a potential problem at the fringe of the patterning field, where $\mathrm{HH}$ protein may not be concentrated enough for pathway activation and requires signal enhancing mechanisms. Understanding the mechanisms through which $\mathrm{HH}$ signaling strength is regulated is of great importance for understanding not only embryogenesis but also genetic diseases and cancers caused by misregulated $\mathrm{HH}$ signaling (McMahon et al. 2003; Xie 2005; Kayed et al. 2006).

Gas1 (Growth Arrest-Specific Gene 1) encodes a 37$\mathrm{kDa}, \mathrm{N}$-glycosylated, and glycosylphosphatidyl inositol (GPI)-linked plasma membrane protein. It was first discovered as a negative cell cycle regulator and tumor suppressor in cultured cells (Schneider et al. 1988; Del Sal et al. 1994; Evdokiou and Cowled 1998). We found that GAS1 has a high affinity for $\mathrm{HH}$ and suggested that it has a potential role in regulating $\mathrm{HH}$ signaling (Lee et al. 2001a). However, the role for Gas1 in HH signaling during normal development has not been established. Here we present a direct measure of the genetic interaction between Gas1 and Shh to demonstrate that Gas1 is an enhancer of $\mathrm{HH}$ signaling, particularly at a long distance and/or at low concentrations. Combined with the finding that $\mathrm{HH}$ signaling negatively regulates Gas1 expression, we propose a model in which GAS1 fine-tunes the $\mathrm{HH}$ activity gradient. 
Results

Generation of the Gas $1^{\text {Lacz }}$ allele

To facilitate visualization and study the regulation of Gas1 expression, we generated a mouse line in which the Gas1 coding region is replaced by a $L a c Z$ gene. The LacZ reporter activity reproduces the expression pattern of Gas1 as previously obtained by in situ hybridization (ISH) (Supplementary Fig. S1; Lee and Fan 2001). Mice heterozygous for this mutant allele are phenotypically normal, and homozygous mutant embryos have the same phenotypes as the original Gas1 mutant; for example, defects in the limb and eye (Lee et al. 2001b; Liu et al. 2002). This $L a c Z$ allele was used for all genetic crosses in this study and is referred to as Gas1- for simplicity.

\section{Gas1 and Shh interact genetically}

Overexpression of Gas1 in tissue explants demonstrated that it could function as an antagonist to $\mathrm{HH}$ signaling in vitro (Lee et al. 2001a; Cobourne et al. 2004). To test this in vivo, we sought to define the relationship between Gas1 and Shh by genetic analysis. We generated mice that were double heterozygous for $\mathrm{Gas1}^{-}$and a mutant

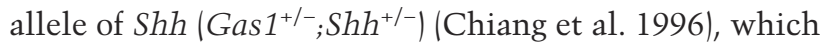
were phenotypically normal. These mice were interbred to obtain embryos of allelic combinations for analysis. Morphological analysis of neonatal mice revealed that Gas1 $^{-/-} ; \mathrm{Shh}^{+/-}$mice have a single nostril as opposed to the normal two found in $\mathrm{Gas1}^{+/-} ; \mathrm{Shh}^{+/-}$and $\mathrm{Gas1}^{-/-}$ mice (Fig. 1A-C). Narrowing and fusion of midline facial structures represents a mild holoprosencephaly, a birth defect associated with impaired SHH signaling (Roessler

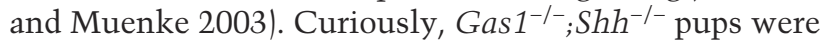
not found at birth, suggesting embryonic lethality. We found that the double mutants were only recovered at a ratio (0.053) close to the Mendelian ratio (0.0625) at $9.5 \mathrm{~d}$ of embryonic development (E9.5) (Fig. 1D), unlike $\mathrm{Shh}^{-1-}$ or $\mathrm{Gas1}^{-/-}$embryos, which can survive to term. $\mathrm{Gas1}^{-/-}$;Sh ${ }^{-/-}$embryos were less frequently recovered at E10.5, but were morphologically arrested at E9.5, indicating lethality around E9.5.

Gross morphological examination of E9.5 embryos revealed that the Gas1; Shh double mutants were more severely affected than either single mutant. The double mutants had a reduced size and inflated pericardium, and failed to undergo proper embryonic turning, resulting in a double-kink in the body axis or an L-shaped body axis (Fig. 1E-H). They also had severe cardiac edema, presum-

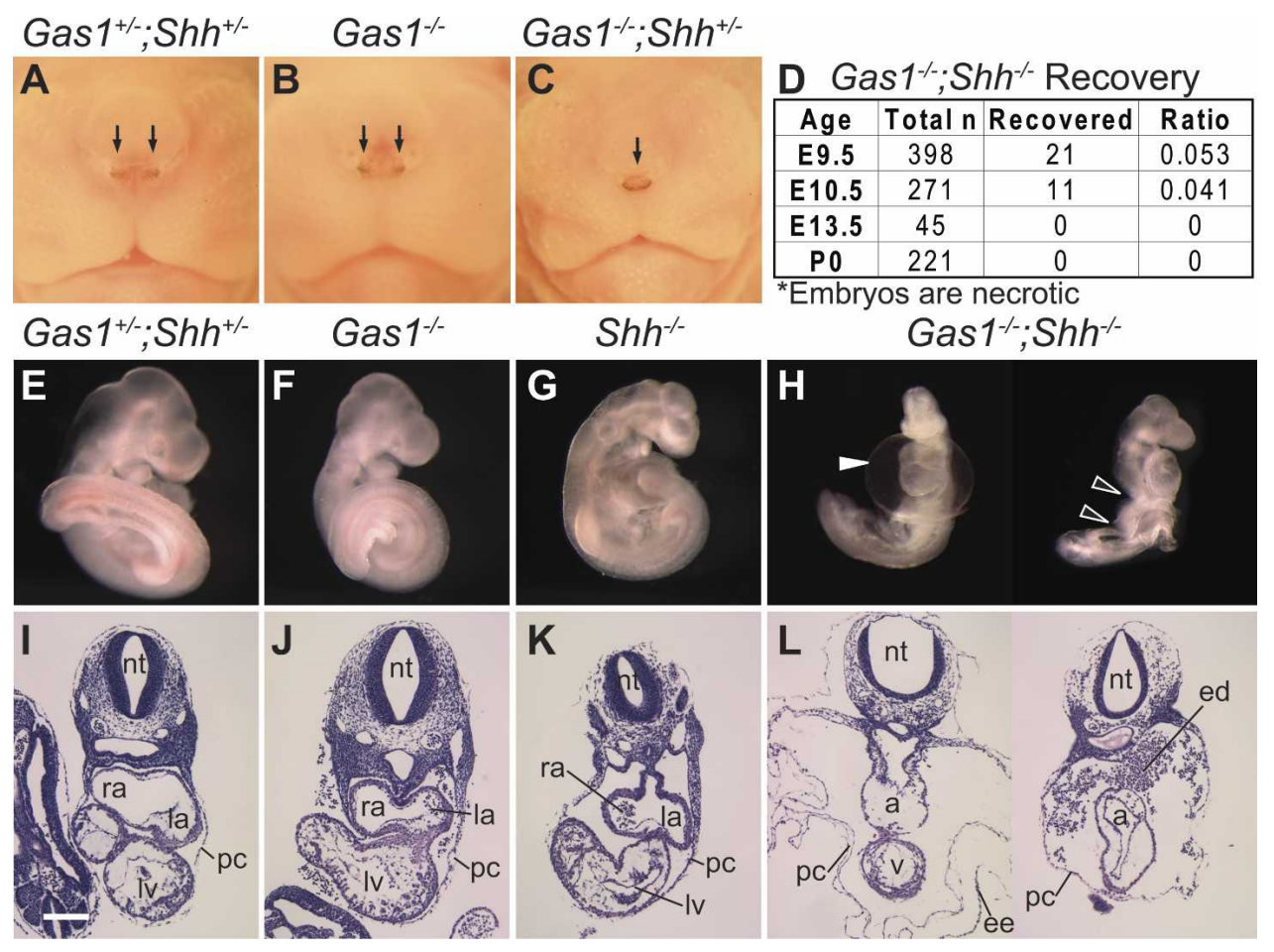

Figure 1. A genetic interaction exists between Gas1 and Shh. Neonatal control $(A)$ and Gas1 ${ }^{-/-}(B)$ mice have two nostrils (arrows), while Gas1 $^{-/-} ; \mathrm{Shh}^{+/-}(\mathrm{C})$ mice have one $(n=5)$. (D) The table shows the recovery of $\mathrm{Gas1}^{-1-}$; $\mathrm{Shh}^{-/-}$embryos at different stages from crosses between Gas $^{+/-}$; $S h h^{+/-}$mice. $(E-H)$ Gross morphology comparison between day 9.5 embryos of different genotypes (as labeled): The Gas1 $^{-1-} ; S_{h h^{-/}}$embryos have an inflated pericardium (arrowhead, ventral view) and a double-kinked body axis (open arrowheads, lateral view with pericardium removed). $(I-L)$ Hematoxylin and eosin staining of transverse sections at similar levels of the heart at E9.5: For the $\mathrm{Gas1}^{-/-}$; $\mathrm{Shh}^{-/-}$embryos, note the failed heart tube looping compared with the other genotypes; in the right panel of $L$, the ventricle is not present at this level of section. (a) Atrium; (ed) edema; (ee) extra embryonic membrane; (la) left atrium; (lv) left ventricle; (nt) neural tube; (pc) pericardium; (ra) right atrium; (v) ventricle. Bar: $I-L, 200 \mu \mathrm{m}$. 
ably the cause of lethality. Histological analysis of transverse sections at the level of the heart reveals a linear or mostly linear heart tube in the $\mathrm{Gas1}^{-1-} ; \mathrm{Shh}^{-/-}$embryos (Fig. 1I-L), indicating a defect in left/right heart asymmetry, a process dependent on combined SHH and IHH signaling in the node (Zhang et al. 2001).

The morphological defects described above for Gas1 $^{-1-} ; \mathrm{Shh}^{-/-}$embryos are similar to but not as severe as those described for $\mathrm{Smo}^{-1-}$ and $\mathrm{Shh}^{-1-} ; \mathrm{Ihh}^{-1-}$ embryos, both of which have a complete loss of early embryonic HH signaling (Zhang et al. 2001). These correlations and genetic interactions described above lead us to propose that Gas1 acts positively in $\mathrm{HH}$ signaling, instead of the previously proposed antagonistic relationship obtained in vitro (Lee et al. 2001a; Cobourne et al. 2004).

\section{Gas1 facilitates HH signaling in the neural tube and somite}

To define Gas1's genetic contribution to $\mathrm{HH}$ signaling at the molecular level, we examined the somites and neural tube of $\mathrm{Gas1}^{-/-}$and $\mathrm{Gas1}^{-1-} ; \mathrm{Shh}^{-/-}$embryos. The somites are the embryonic precursors that form the vertebrae and ribs, while the neural tube forms the spinal cord at the trunk level. HH signaling regulates the pattern of gene expression along the dorso-ventral axis of both systems. SHH is the primary source, secreted first from the notochord located just ventral to the neural tube, and then from the floorplate after it is induced by the notochord (Fig. 2U; Litingtung and Chiang 2000a). Localized $\mathrm{HH}$ positively regulates downstream gene expression in the ventral portions of the somites and neural tube, and negatively regulates genes to restrict their expression to the dorsal somite and neural tube. If Gas1 acts positively in HH signaling, then when Gas1 function is removed, we expect to observe reductions in ventral marker expression and expansions in dorsal marker expression.

To monitor the dorso-ventral polarity of the somite at the forelimb level of E9.5 embryos, we used Pax1, a ventral marker activated by $\mathrm{HH}$, as well as Pax3 and PAX7, dorsal markers repressed by HH (Fan and TessierLavigne 1994). In the Gas1 $1^{-/-}$somite, the Pax1 domain appeared not to extend as far dorsally compared with the Gas1 $^{+-}{ }^{\text {; }} \mathrm{Shh}^{+/-}$control (Fig. 2A,B), while the domains of Pax3 and PAX7 appeared normal (Fig. 2E,F,I,J). In the $\mathrm{Shh}^{-/-}$embryo, residual $\mathrm{HH}$ signaling to the somite is still present due to partial compensation by IHH secreted from the endoderm located ventral to the notochord (Zhang et al. 2001). As published, we found that there was Pax1 expression in the $\mathrm{Shh}^{-1-}$ somite, but at a reduced level and more ventrally restricted (Fig. 2C), while Pax3 and PAX7 expression was ventrally expanded (Fig. 2G,K; Chiang et al. 1996). In the Gas1 $^{-/-}$; Shh ${ }^{-/-}$embryo, Pax1 expression was absent, suggesting a loss of $\mathrm{HH}$ pathway activation in the somites (Fig. 2D). Consistent with this, Pax3 and PAX7 expression in the double mutant expands farther ventrally than in the Shh mutant (Fig. 2H,L). These results suggest that Gas1 acts positively in $\mathrm{HH}$ signaling to the somites, and that its ge- netic contribution is particularly significant when the somite is only exposed to low-level $\mathrm{HH}$ signaling as in the Shh mutant.

$\mathrm{HH}$ primarily secreted from the notochord specifies multiple cell types in the ventral neural tube in a concentration-dependent manner (Ericson et al. 1995a,b; Tanabe et al. 1995; Briscoe et al. 1999). Among these cell types, the floorplate requires the highest $\mathrm{HH}$ concentration (via a contact-dependent process), while the p0 progenitors require the lowest (Briscoe et al. 2001; Pierani et al. 2001). Based on the above findings, we examined markers known to be indicative of low-level $\mathrm{HH}$ signaling: $D b \times 1$, which is expressed specifically in the 0 progenitors, and $P a x 3$ and PAX7, which are restricted to the dorsal neural tube due to repression by $\mathrm{HH}$ (Ericson et al. 1996). Importantly, the expression domains of these genes are encompassed by the Gas1 expression domain (data not shown). In the E9.5 Gas1 $^{-/-}$embryo at the forelimb level, the $D b x 1$ expression domain was ventrally expanded (Fig. 2M,N; Supplementary Fig. S2). The ventral boundaries of $\operatorname{Pax} 3$ and PAX7 expression shifted slightly ventrally as well (Fig. 2E,F,I,J; Supplementary Fig. S2). Quantitation of marker expression boundaries and additional marker analysis were performed to document the neural tube defect of $\mathrm{Gas1}^{-/-}$and $\mathrm{Gas1}^{-1-} ; \mathrm{Shh}^{+-}$embryos in Supplementary Figure S2. These data collectively indicate that in the Gas $1^{-/-}$background, there is reduced $\mathrm{HH}$ signaling.

As previously described, $D b \times 1$ expression in the $\mathrm{Shh}^{-/-}$neural tube was shifted ventrally to the midline (Fig. 2O) accompanied by the ventral expansion of Pax3 and PAX7 expression (Fig. 2G, $\mathrm{K}$; Litingtung and Chiang 2000b; Wijgerde et al. 2002). This Dbx1-positive domain is most likely mediated by diffusible IHH from the endoderm (Zhang et al. 2001; Wijgerde et al. 2002). In the Gas1 $^{-1-} ; \mathrm{Shh}^{-1-}$ neural tube, there was a complete lack of Dbx1 expression (Fig. 2P), and Pax3 and PAX7 expression expanded farther ventrally to encompass the entire neural tube (Fig. $2 \mathrm{H}, \mathrm{L})$. Thus, although the defect of the Gas1 $^{-1-}$ neural tube is subtle, Gas1's contribution to IHH signaling becomes clear in the sensitized Shh ${ }^{-/-}$ background. This conclusion is further confirmed by the expression of the HH target Ptc1 (Goodrich et al. 1996; Marigo and Tabin 1996), which becomes progressively more ventrally restricted from the $\mathrm{Gas1}^{+/-}$; $\mathrm{Shh}^{+/-}$, to the Gas1 $^{-1-}$, the Shh ${ }^{-1-}$, and finally the $\mathrm{Gas1}^{-1-} ; \mathrm{Shh}^{-/-}$genotype (Fig. 2Q-T). There remains residual Ptc1 expression in the $\mathrm{Gas1}^{-1-}$; $\mathrm{Shh}^{-/-}$neural tube, likely due to its basal transcription level.

While the above results suggest that Gas1 facilitates $\mathrm{HH}$ signaling, it is also possible that Gas1 regulates $\mathrm{HH}$ expression. To test this, we examined the expression of $\mathrm{IHH}$ and Shh. We found that IHH production in the endoderm is similar between the $\mathrm{Gas1}^{-/-} ; \mathrm{Shh}^{-/-}$embryo and the $\mathrm{Shh}^{-/}$embryo (Fig. 2W,X), supporting that in the $\mathrm{Shh}^{-1-}$ embryo, Gas1 facilitates IHH signaling to the neural tube and somites. In Gas1 $1^{-/-}$embryos, we found normal levels of Shh expression in the notochord. Interestingly, we found a narrow, triangular-shaped floorplate instead of the normal wedge shape, reflected by a 
Figure 2. Compensation provided by $\mathrm{IHH}$ signaling in the $\mathrm{Shh}^{-1-}$ background is eliminated in Gas1 $^{-/-}$; Shh ${ }^{-/-}$embryos. (A-D) Pax1 ISH $(n=11) .(E-H)$ Pax3 ISH $(n=15) .(I-L)$ PAX7 IHC $(n=9)$. $(M-P) D b x 1$ ISH $(n=5)$. (QT) Ptc1 ISH $(n=11)$. Arrowheads indicate the dorsal or ventral extent of gene expression; lines in $E-H$ indicate the domain size of $\mathrm{Pax} 3$ and PAX7. $(U, V)$ Shh ISH $(n=3)$; brackets indicate the width of $S h h$-expressing floorplate cells; images are at $2 \times$ higher magnification. $(W, X) \mathrm{IHH}$ IHC $(n=2)$; arrows indicate the apical localization of $\mathrm{IHH}$ protein. All sections are transverse at the forelimb level of E9.5 embryos. Genotypes are labeled on top of each panel. Not shown are $\mathrm{Gas1}^{+/-} \mathrm{Shh}^{-1-}$ embryos, which display a variable but intermediate phenotype between $S h h^{-/}$and Gas1 $^{-1-}$; Shh ${ }^{-1-}$. Axis: Dorsal is up, ventral is down. Bars: all except for $U, V, 100 \mu \mathrm{m} ; U, V$, $50 \mu \mathrm{m}$.
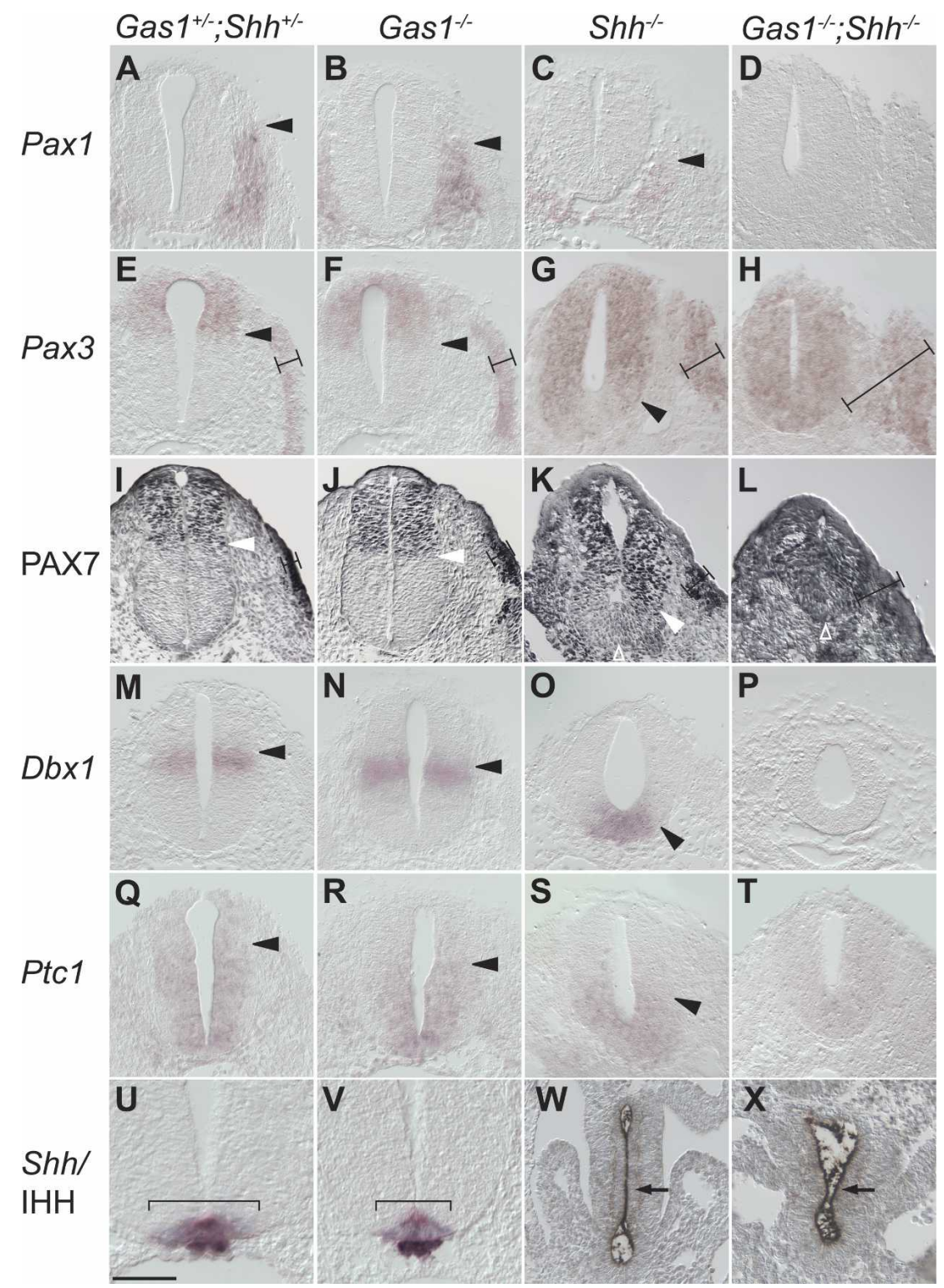

reduced Shh expression domain (Fig. 2U,V). This suggests that Gas1 aids SHH signaling from the notochord to induce the floorplate. Gas1 is expressed throughout the entire neural tube at earlier stages of development during floorplate induction (data not shown; see below), consistent with a role for Gas1 in floorplate induction. However, the relative contribution to the Gas1 $1^{-/-}$neural tube phenotype at E9.5 caused by the lack of Gas1 versus a secondary consequence of the reduced size of the Shhpositive floorplate is not clear.

\section{Gas1 facilitates low-level SHH signaling in the limb}

The above-described phenotypes suggest that either Gas1 generally facilitates HH signaling or that Gas1 acts preferentially with IHH. To test whether Gas1 also facilitates $\mathrm{SHH}$, we examined the developing limbs, an established system for studying $\mathrm{SHH}$ signaling without input from other $\mathrm{HH}$ homologs. A current model for the role of $\mathrm{SHH}$ in patterning digit number and identity along the anterio-posterior $(\mathrm{A} / \mathrm{P})$ axis states that digit 1 is $\mathrm{SHH}$-independent; digit 2 and the anterior part of digit 3 receive only diffusible $\mathrm{SHH}_{\text {; }}$ and digits 4 and 5 and the posterior part of 3 are specified at least in part by the different lengths of time exposed to local SHH signaling (Chiang et al. 2001; Kraus et al. 2001; Ahn and Joyner 2004; Harfe et al. 2004). If Gas1 also facilitates SHH signaling, we would expect impaired digit specification by removing Gas1 function.

To test this, skeletal preparations of neonatal $\mathrm{Gas1}^{+/-} ; \mathrm{Shh}^{+/-}, \mathrm{Gas1}^{-/-}$, and $\mathrm{Gas1}^{-/-} ; \mathrm{Shh}^{+/-}$limbs were performed. Digit numbers on limbs were scored as having either a normal five digits, four, or 4.5 (five digits with digit 2 being fused to either digit 1 or 3 ). When 


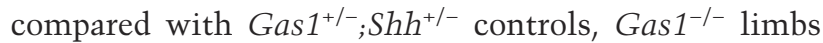
had an overall reduced size, a disproportionately smaller digit 2 (Supplementary Fig. S3), and hypodactyly at a low penetrance $15 \%$ of forelimbs and $41 \%$ hindlimbs had 4.5 digits; $42 \%$ of hindlimbs were missing digit 2) (Fig. 3, cf. $\mathrm{A}, \mathrm{D}$ and $\mathrm{B}, \mathrm{E})$, similar to the previously reported Gas1 mutant (Liu et al. 2002). While the size of the limb remained constant, the digit 2 hypodactyly phenotype became exacerbated when $S h$ dosage was reduced in the $\mathrm{Gas1}^{-/}$; $\mathrm{Shh}^{+/-}$background $16 \%$ of forelimbs had 4.5 digits; $84 \%$ of forelimbs and $100 \%$ of hindlimbs were missing digit 2) (Fig. 3C,F). Our rationale for suggesting that 2 is the identity of the missing digit is based on the morphology of the remaining digits and time-course

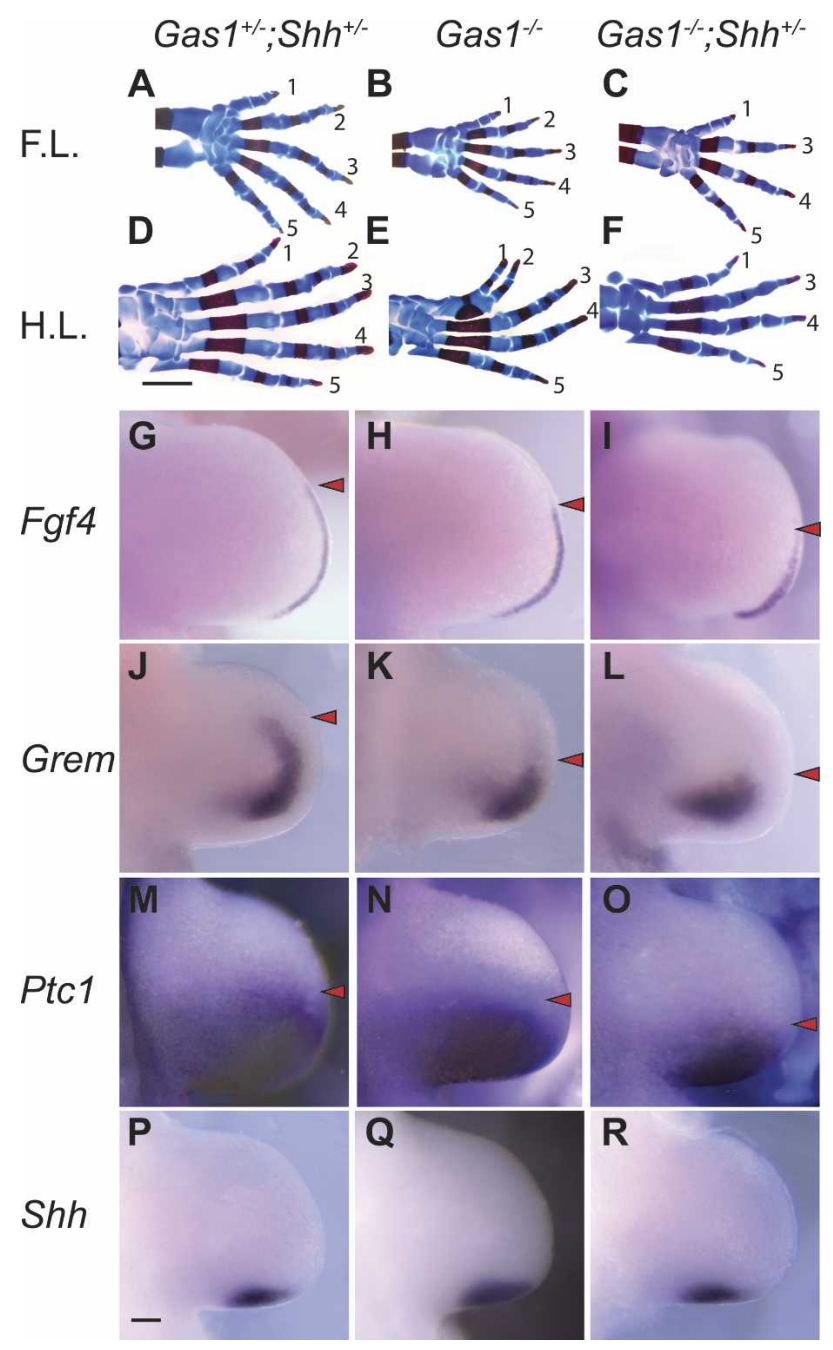

Figure 3. Gas1 $1^{-/-} ; \mathrm{Shh}^{+/-}$limbs have reduced range of SHH signaling. $(A-F)$ Alcian blue-stained (for cartilage) and alizarin redstained (for bone) neonatal forelimb (F.L.) and hindlimb (H.L.) autopods of $\mathrm{Gas1}^{+/-}$; $\mathrm{Shh}^{+--}(A, D)(n=22)$, Gas1 $^{-1-}(B, E)(n=22)$, and $\mathrm{Gas1}^{-1-} ; \mathrm{Shh}^{+--}(C, F)(n=19)$ genotypes. $(G-R)$ Whole-mount ISH of E10.5 forelimb buds: $(G-I) F g f 4(n=6)$. $(J-L)$ Grem $(n=3)$. $(M-O)$ Ptc1 $(n=7)$; Gli1 (not shown; $n=5)$; arrowheads mark the anterior boundary of expression. $(P-R) \operatorname{Shh}(n=5)$. Axis: Anterior is up, posterior is down. Bars: $A-F, 1 \mathrm{~mm} ; G-R, 100 \mu \mathrm{m}$. analysis revealing that a digit at the digit 2 position never forms in the Gas1 $^{-/-} ; \mathrm{Shh}^{+/-}$genotype (Supplemen-

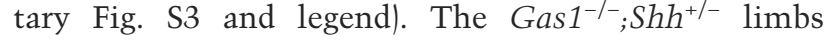
closely resemble those hypomorphic for Dispatched (in a

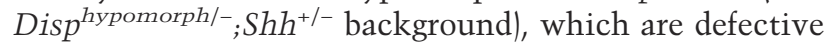
in long-range SHH signaling and specifically lack digit 2 (Harfe et al. 2004). Together, these results support the model that Gas1 facilitates long-range $\mathrm{SHH}$ signaling in the limb.

If this hypothesis is correct, then we expect to find a reduction in the expression of $\mathrm{SHH}$ downstream genes in the E10.5 limb bud, an early time period when SHH acts upon the limb. Shh is expressed in a posterior region of mesenchyme known as the Zone of Polarizing Activity (ZPA) (Fig. 3P). From E9.25, a stage prior to Shh expression in the ZPA, to E11.5, Gas1 is not expressed in the posterior mesenchyme (see below; Liu et al. 2002). Ptc1 and Gli1 are SHH target genes, while Fgf4 and Grem are indirectly activated, but their expression is also indicative of the range of $\mathrm{SHH}$ signaling. All are expressed in the mesenchyme, except for Fgf4, which is expressed in the Apical Ectodermal Ridge. Whole-mount ISH for these target genes reveals a more posteriorly restricted expression domain in the Gas1-/- limb bud when compared with the Gas1 $^{+/-}$;Shh ${ }^{+-}$limb bud (Fig. 3, cf. G,J,M and $\mathrm{H}, \mathrm{K}, \mathrm{N}$; data not shown). A further restriction is seen in the $\mathrm{Gas1}^{-/-}$; Shh ${ }^{+-}$limb bud (Fig. 3I,L,O; data not shown). Importantly, target gene expression in the posterior regions close to or in the ZPA was unaffected, regions where Gas1 is not expressed. Shh expression is not reduced in the $\mathrm{Gas1}^{-/-} ; \mathrm{Shh}^{+/-} \mathrm{limb}$ when compared with that in the $\mathrm{Gas1}^{+/-} ; \mathrm{Shh}^{+-} \mathrm{limb}$, indicating that the results of the marker analysis are not caused by Shh down-regulation (Fig. 3P,R). Therefore, our molecular analysis supports that Gas1 is required for the full range of $\mathrm{SHH}$ signaling in the limb. More specifically, Gas1 facilitates $\mathrm{SHH}$ signaling where it is expressed, which in the case of the limb bud corresponds to regions reached by only long-range and thus low-level SHH signaling.

SHH signaling inhibits the processing of the GLI3 (190 $\mathrm{kDa}$ ) transcription factor into smaller forms (83 and 75 $\mathrm{kDa}$ ), which function as strong transcriptional repressors (GLI3-R) (Wang et al. 2000). For patterning of digit number and identity, it is thought that the primary action of the SHH gradient in the limb bud is to establish a countergradient of the ratio of the GLI3-R to unprocessed GLI3 (GLI3-R:GLI3-190) (Litingtung et al. 2002). In the absence of Gli3, limbs form an array of seven to nine digits, each without a clear identity; this is observed regardless of the presence of $S h$ - that is, Gli3 is epistatic to Shh (Litingtung et al. 2002). Based on the above results that Gas1 facilitates $\mathrm{HH}$ signaling in the limb, we predict Gli3 to also be epistatic to Gas1 in digit patterning. To test this, we analyzed $\mathrm{Gli3}^{-{ }^{-}}$and $\mathrm{Gas1}^{-{ }^{-}} ; \mathrm{Gli3}^{-{ }_{-}}$ limb digit patterns by skeletal preparation and observed that the polydactyly phenotype of $\mathrm{Gli3}^{-/-}$limbs is indistinguishable from that of $\mathrm{Gas}^{-/-} ; \mathrm{Gli3}^{-/-}$limbs, consistent with our hypothesis (Fig. 4A). Additionally, we predict to observe increases in the processing of GLI3-190 in 
Figure 4. Gli3 is epistatic to Gas1 in digit patterning, and Gas1 inhibits GLI3 processing. (A) Alcian blue- and alizarin red-stained E16.5 forelimb (F.L.) and hindlimb (H.L.) autopods of $\mathrm{Gli3}^{-/-}$and $\mathrm{Gas1}^{-{ }^{-}} ; \mathrm{Gli3}^{-/-}$limbs $(n=5)$. Bar, $1 \mathrm{~mm}$. (B) Diagram depicting how E10.5 limb buds were dissected. (C) Western blot analysis for GLI3 on indicated genotype and limb bud halves. (A) Anterior; (P) posterior. GLI3-190 and GLI3-R bands are as labeled. A Gli3 ${ }^{-1-}$ limb bud was used for a control. Blots were stripped and reprobed for $\alpha$-tubulin for a loading control. Asterisks indicate nonspecific bands. $(D)$ Western blot repeated for three embryos of each genotype and band intensity quantified. GLI3-R:GLI3190 ratios are indicated.
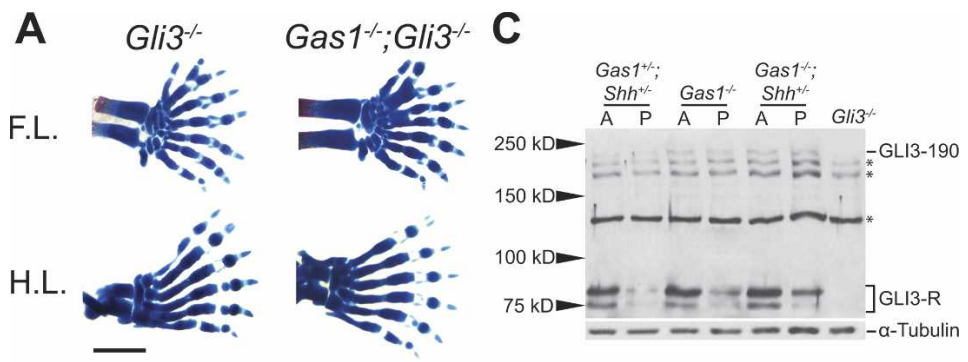

B

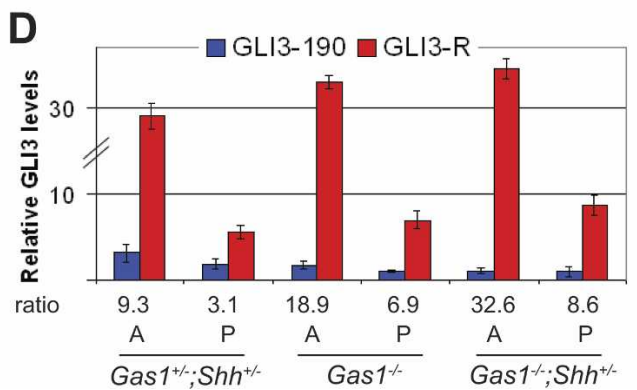

E10.5 limb buds that correlate with the phenotypes of the Gas1 $^{-/-}$and $\mathrm{Gas1}^{-1-} ; \mathrm{Shh}^{+/-}$limbs. To test this, we harvested E10.5 limb buds, dissected each into anterior and posterior halves (Fig. 4B), and performed Western blot analysis using an antibody that recognizes all GLI3 forms (Fig. 4C). The intensity of the GLI3-190 and GLI3-R bands was quantified and normalized to $\alpha$-tubulin, and the GLI3-R:GLI3-190 ratio was calculated (Fig. 4D). Similar to previously reported results, we found that the ratio was 9.3 in the anterior of control limb buds and 3.1 in the posterior (Wang et al. 2000). Importantly, in the $\mathrm{Gas1}^{-/-}$and $\mathrm{Gas1}^{-/-} ; \mathrm{Shh}^{+/-}$buds, these ratios were increased by approximately twofold and threefold, respectively. How the measured changes of GLI3 isoform ratios in the mutant limbs are translated into the final digit patterns remains unresolved. However, the genetic and biochemical analyses above demonstrate that the relationship between Gas1 and Gli3 is consistent with Gas1 facilitating $\mathrm{HH}$ signaling.

\section{Gas1 enhances the activity of SHH}

Taken together, our genetic analysis strongly supports a model in which Gas1 is required for the complete range of $\mathrm{HH}$ signaling. We next investigated two possible mechanisms for how GAS1 could facilitate HH signaling, which are not necessarily mutually exclusive. First, GAS1 could enhance the diffusion or transport of $\mathrm{HH}$ protein to cells distant from the source of $\mathrm{HH}$ synthesis. Second, after HH has arrived at a target cell, GAS1 could enhance the ability of $\mathrm{HH}$ to induce signal transduction; that is, $\mathrm{HH}$ activity. To differentiate between these two possibilities, we first examined the distribution of $\mathrm{SHH}$ in E10.5 limb buds in the various allelic combinations of Gas1 and Shh using immunohistochemistry (IHC), an established method used to determine the range of $\mathrm{SHH}$ diffusion (Gritli-Linde et al. 2001; Lewis et al. 2001;
Harfe et al. 2004). We found no detectable difference in the domain of SHH between the $\mathrm{Gas1}^{+/-} ; \mathrm{Shh}^{+/-}$and $\mathrm{Gas1}^{-1-}$; $\mathrm{Shh}^{+/-}$genotypes (Fig. 5A) in contrast to the reduced SHH domain observed in the Disp ${ }^{\text {hypomorph/- }} ; \mathrm{Shh}^{+/}$ limb bud (Harfe et al. 2004). Western blot analyses of E10.5 limb buds also showed that total SHH protein is not reduced in the $\mathrm{Gas1}^{-/-} ; \mathrm{Shh}^{+/-} \mathrm{limb}$ bud when compared with $\mathrm{Gas1}^{+/-}$; $\mathrm{Shh}^{+/-}$, indicating that SHH production and stability are not altered (data not shown). However, since IHC may not be sensitive enough to detect the entire range of SHH distribution, it is possible that a subtle change in SHH diffusion might escape our detection.

The lack of evidence for a change of SHH diffusion in the Gas1 mutant limbs led us to test whether GAS1 enhances SHH signaling activity. We chose to use an in vitro system uncomplicated by dependence on SHH diffusion. NIH3T3 cells with a stably integrated HH-responsive luciferase reporter gene driven by GLI-binding sites (NIH3T3-GLI-Luc) were transfected with either control or targeted short interfering RNA (siRNA) against the Gas 1 transcript. This method lowered GAS1 levels by $\sim 90 \%$ with siRNA against Gas1 but not with control siRNA (Fig. 5B, inset). We then exposed these cells to various concentrations of $\mathrm{SHH}$ (conditioned media containing SHH N-terminal product, SHH-N without cholesterol modification) and assayed for $\mathrm{HH}$ responsiveness. Between the low concentrations of SHH-N tested, $0.75-12 \mathrm{nM}, \mathrm{HH}$ responsiveness is approximately twofold reduced when GAS1 is down-regulated, compared with cells transfected with control siRNA (Fig. 5B). At concentrations $>12 \mathrm{nM}$, the control cell's $\mathrm{HH}$ response becomes saturated, while the GAS1 down-regulated cells continue to show progressive increases in $\mathrm{HH}$ responsiveness. At $24 \mathrm{nM}$, the difference in fold induction between the control and GAS1 down-regulated cells becomes statistically insignificant. The physiological 

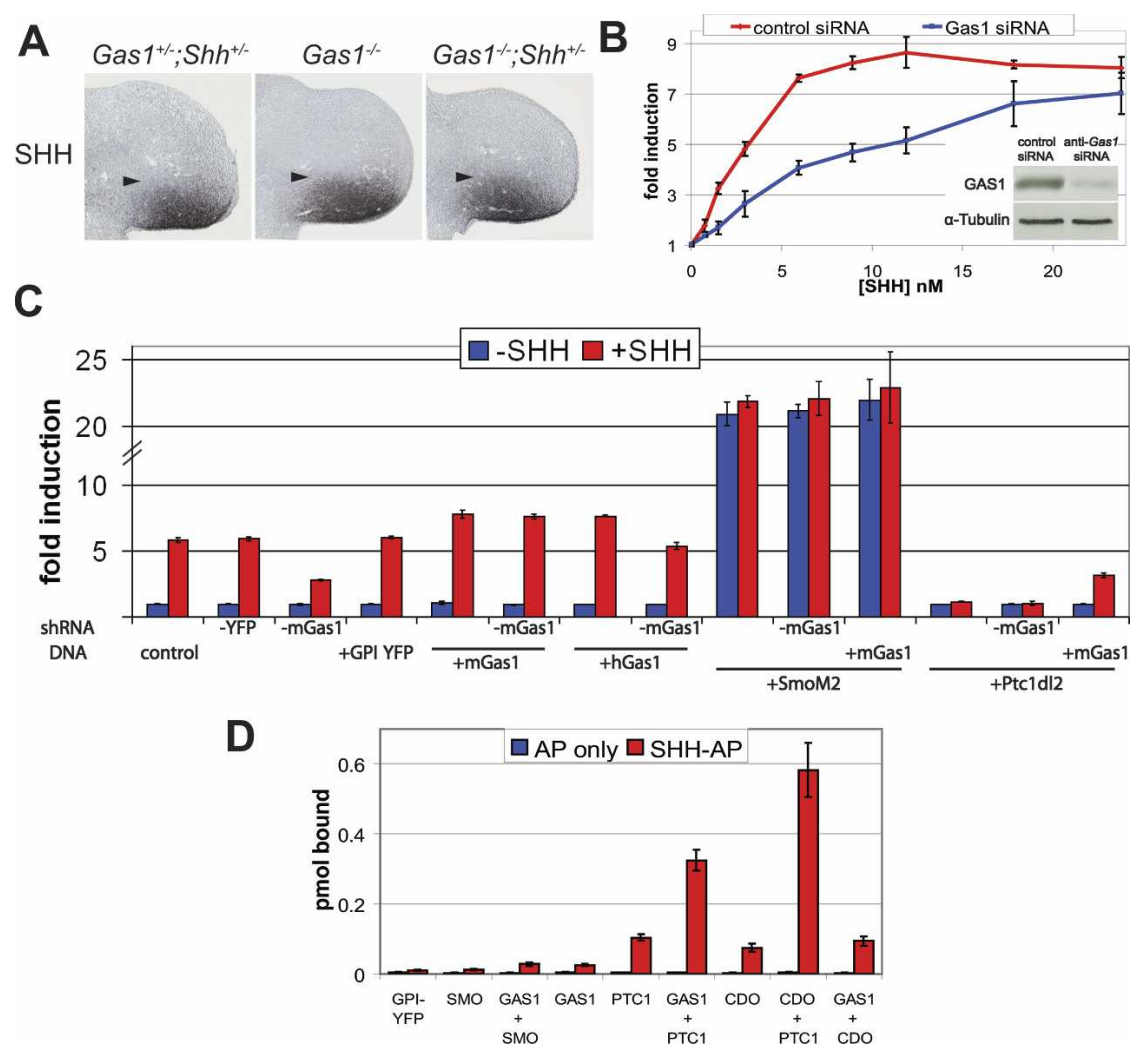

Figure 5. GAS1 facilitates $\mathrm{SHH}$ signaling activity. (A) SHH IHC on horizontal sections of E10.5 limb buds $(n=10)$ of labeled genotypes; arrowheads mark the anterior boundary of detectable SHH. For color development, Gas1 mutant limbs were developed for approximately half as long to compensate for the doubled Shh dosage. (B) Fold induction ( $Y$-axis) of NIH3T3-GLILuc cells transfected with control siRNA or Gas1 siRNA by various concentrations of SHH-N ( $X$-axis); (inset) Western blot for GAS1, then reprobed for $\alpha$-tubulin as a loading control. $(C)$ Fold induction $(Y$-axis) of NIH3T3 cells transiently cotransfected with GLI-Luc reporter and plasmids expressing various effector genes and/or shRNA against Gas1 (as labeled) in the presence or absence of $10 \mathrm{nM}$ SHH-N. $(D)$ SHH-N-AP-binding assay of COS cells expressing Gas1 and/or Ptc1, as well as other control genes are as labeled. They were assayed for binding to SHH-N-AP or AP alone, as determined by the picomoles bound ( $Y$-axis) (input $=1.25 \mathrm{nM})$. In $B-D$, all assays were performed in triplicate; error bars $=1$ standard deviation.

relevance of $\mathrm{SHH}$ concentrations above the saturation threshold determined for the NIH3T3 cell line is unknown. It is also unclear how much further a reduction in $\mathrm{SHH}$ responsiveness would be observed if the siRNA treatment removed all GAS1 protein. Nonetheless, our results suggest that GAS1 indeed enhances $\mathrm{HH}$ signaling activity.

To confirm this result with an alternate method, we transiently transfected NIH3T3 cells with the GLI-luciferase reporter and an expression construct for short hairpin RNA (shRNA) against a region in the Gas1 3' untranslated region (UTR) that is a different sequence from that used above. At a concentration of SHH-N just below the threshold of maximal response $(10 \mathrm{nM})$, we find a similar approximately twofold reduction in reporter activity when Gas1 transcripts were targeted by shRNA compared with the empty shRNA vector control or to shRNA against YFP (Fig. 5C). Conversely, cotransfection with an expression construct for mouse Gas1 (mGas1) causes a modest increase in the $\mathrm{HH}$ response, while expression for a GPI-anchored YFP has no effect. Importantly, the decrease in $\mathrm{HH}$ responsiveness caused by shRNA against Gas1 can be rescued by coexpressing a mGas1 cDNA without the shRNA target sequence. Similarly, an expression construct for human Gas1 (hGas1), which is not a target for the shRNA, could also rescue the $\mathrm{HH}$ response, indicating that hGas1 can function in a similar way as the mGas1 (Fig. 5C). Thus, we conclude that GAS1 activity is required for maximal $\mathrm{HH}$ response in NIH3T3 cells.

Because GAS1 binds to $\mathrm{HH}$ at the cell surface (Lee et al. 2001a), we predict that it acts either at the level of PTC1 or SMO. To test this, we used the above cell culture reporter system to place GAS1 in the $\mathrm{HH}$ pathway relative to PTC1 and SMO. As expected, when an activating form of Smo, SmoM2 (Buttitta et al. 2003), was expressed in the NIH3T3 cells, the $\mathrm{HH}$ pathway was strongly activated independently of $\mathrm{HH}$ (Fig. 5C). Either overexpressing Gas1 or knocking down Gas1 did not alter the activity of SmoM2 in the presence or absence of $\mathrm{HH}$, suggesting that GAS1 acts at or above the level of SMO. Conversely, when a non-HH-binding form of Ptc1, delta-loop2-Ptc1 (Ptc1dl2) (Briscoe et al. 2001), was expressed, HH-dependent pathway activation through the endogenous receptor PTC1 was repressed. While reducing GAS1 did not alter the dominant effect of Ptc1dl2 as expected, expressing more Gas1 did partially rescue $\mathrm{HH}$ responsiveness, indicating that the effect of Ptc1dl2 can be overcome by Gas1 overexpression. Taken together, we place GAS1 function above the level of SMO and likely at or below the level of PTC1.

Activation of the $\mathrm{HH}$ pathway by $\mathrm{HH}-\mathrm{PTC} 1$ binding has been proposed to be determined by the ratio between unbound and bound PTC1 (Casali and Struhl 2004). If so, our rescue data predict that increasing GAS1 levels increases the HH-bound PTC1 fraction to overcome the critical ratio required for pathway activation. To investigate this, COS cells transiently expressing either GAS1, PTC1, or simultaneously GAS1 and PTC1 were exposed to conditioned media containing the SHH-Nalkaline phosphatase (SHH-N-AP) fusion protein that allows for quantification of binding (Lee et al. 2001a). As 
predicted, cells expressing either GAS1 or PTC1 bind SHH-N-AP at levels 2.3-fold and 9.5-fold, respectively, greater than cells expressing either GPI-anchored YFP or SMO (Fig. 5D). When both GAS1 and PTC1 were expressed, the amount of SHH-N-AP bound was 29.5-fold higher than in the control cells, an amount greater than the sum of binding provided by GAS1 and PTC1 individually. This indicates that the two proteins display synergism in SHH-N-AP binding and suggests that the positive action of GAS1 on $\mathrm{HH}$ signaling results from an increase in binding of $\mathrm{HH}$ to PTC1. Recently, Ihog was shown to bind $\mathrm{Hh}$ and mediate $\mathrm{Hh}$ signaling in Drosophila (Yao et al. 2006). The mammalian ihog homolog is $C d o$. As a positive control, we confirmed the ability of CDO to bind to SHH-N-AP (6.8-fold) and demonstrated the synergistic binding between CDO and PTC1 (53.0fold) (Fig. 5D, as predicted in Yao et al. 2006). However, we did not observe a synergistic binding of SHH-N-AP between GAS1 and CDO (8.5-fold, approximately equal to the sum of binding providing by GAS1 and CDO individually). This suggests that GAS1 and CDO function independently of each other to facilitate PTC1 binding to SHH-N.

Increasing Gas1 expression enhances $H H$ responsiveness in the neural tube

The above results predict that increasing Gas1 expression should be able to enhance $\mathrm{HH}$ signaling in vivo. To test this directly, we turned to the chick neural tube to take advantage of a powerful gene delivery tool; that is, electroporation. In the chicken neural tube, the Gas1 expression pattern (Lee and Fan 2001) and HH-dependent specification of ventral cell types are similar to those in the mouse (Briscoe and Ericson 1999). We first assessed markers that represent the two ends of the diffusible $\mathrm{HH}$ signaling spectrum: PAX7, whose ventral boundary marks the lowest limit of $\mathrm{HH}$ signaling readout; and
NKX2.2, which labels the p3 progenitors (located just dorsal to the floorplate) (Briscoe and Ericson 1999). For expression, we constructed an expression plasmid with mGas1 cDNA followed by an internal ribosomal entry site-green fluorescent protein (IRES-GFP) cassette to monitor Gas1-expressing cells. The control plasmid expresses a mutant form of GAS1 with an amino acid 155 glutamine $(\mathrm{N})$ to alanine (A) change (i.e., Gas1N/A), which is surface presented but not N-glycosylated and displays minimal SHH binding (Lee et al. 2001a). When the Gas1N/A expression plasmid was electroporated into the left side of the chick neural tube, we saw no alteration of PAX7 (Fig. 6A,B) or NKX2.2 (Fig. 6C,D) expression domains compared with the control right side. In contrast, when the Gas1-expressing plasmid was used, we observed repression of PAX7 when GFP was present in the dorsal neural tube (Fig. 6E,F). When almost all cells on the electroporated side were GFP-positive, ectopic NKX2.2-positive cells could be found halfway up the neural tube, accompanied by reduced NKX2.2 levels at the normal p3 position (Fig. 6G,H). In neural tubes with segregated GFP-positive cells, we found that the PAX7repressed domain was always within the GFP-positive domain (Fig. 6I,J), whereas ectopic NKX2.2-positive cells were always GFP-positive (Fig. 6K,L). Similar marker analysis was performed for HNF3 $\beta$, OLIG2, NKX6.1, and PAX6 in Supplementary Figure S4, and the results are consistent with the conclusions described above. Additionally, we observed that when Gas1 was overexpressed in only the ventral neural tube, inhibition of $\mathrm{HH}$ signaling dorsal to the GFP-positive domain was observed (data not shown), a result probably due to sequestration of $\mathrm{HH}$.

The above results demonstrate the following points: First, ectopic GAS1 can enhance $\mathrm{HH}$ signaling and alter the response gradient in the neural tube; second, this activity of GAS1 depends on its HH-binding property; and third, GAS1 appears to enhance $\mathrm{HH}$ signaling in a cell-autonomous manner. Together with the data that
Figure 6. Gas1 expression alters the position of neuronal progenitors in the neural tube. Chick trunk neural tube was electroporated with Gas1N/A-IRES-GFP $(A-D)$ or Gas1-IRES-GFP $(E-L)$ plasmids and analyzed for GFP $(B, D, F, H, J, L)$, PAX7 $(A, E, I)$, and NKX2.2 $(C, G, K)$ by double immunofluorescence (green for GFP, and red for PAX7 or NXK2.2) on the same sections. Each pair of images $(A$ and $B, C$ and $D$, etc.) is from the same section; $n \geq 10$ for each pair. $I-L$ are at $2 \times$ higher magnification than $A-H$. Brackets indicate altered domains of PAX7 or NKX2.2, arrows indicate corresponding PAX7-negative and GFP-positive domains, arrowheads denote NKX2.2 and GFP doubly positive cells, and open arrowheads indicate the ventral midline.

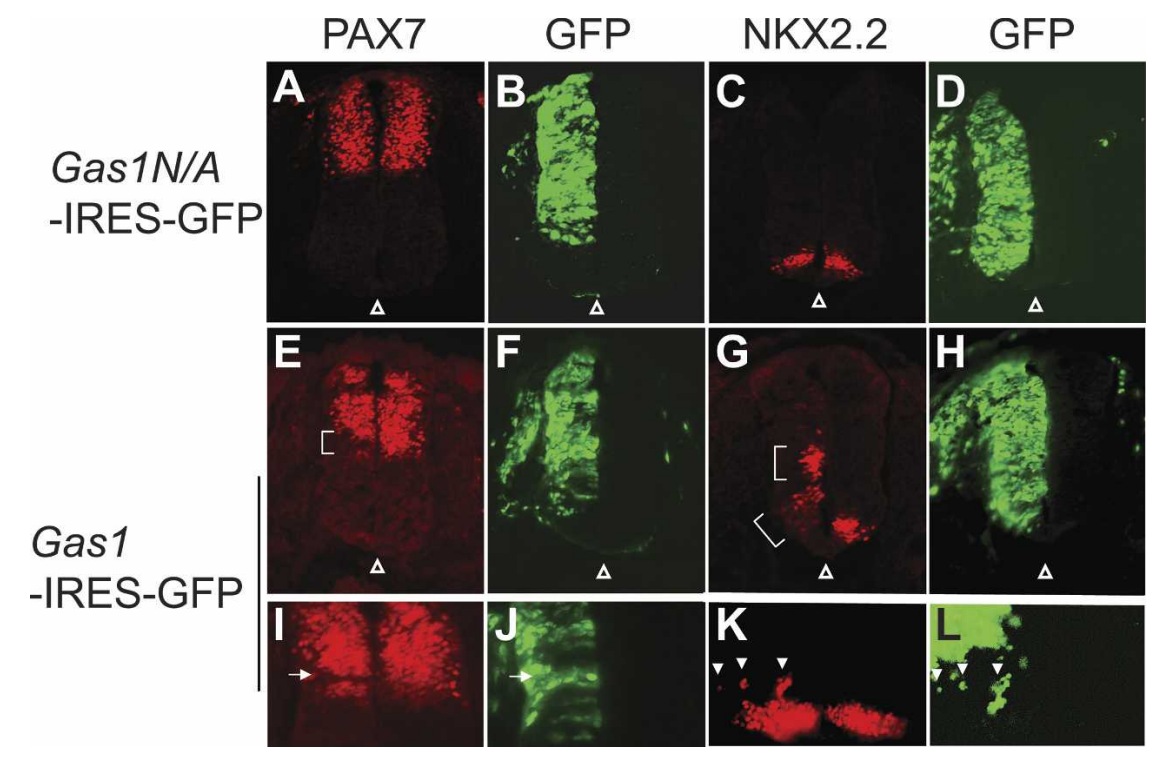


GAS1 and PTC1 display synergistic binding to $\mathrm{SHH}$, our data strongly support the possibility that GAS1 facilitates $\mathrm{HH}$ binding to $\mathrm{PTCl}$ to enhance $\mathrm{HH}$ responsiveness in receiving cells.

\section{Shh regulates Gas1 expression}

The above data indicate that Gas1 acts as a positive regulator of $\mathrm{HH}$ signaling. Somewhat counterintuitively, Gas1 expression levels negatively correlate with $\mathrm{HH}$ signaling levels; that is, Ptc1 expression. This expression pattern implies that Gas1 is repressed by high-level $\mathrm{HH}$ signaling, which may represent a HH self-imposed regulatory loop to modulate its own signaling activity. To test this, we used the LacZ gene knocked into the Gas1 locus to report for Gas1 expression by X-gal staining. In the E9.5 Gas1 $^{+/-}$; $\mathrm{Shh}^{+/-}$embryo at the trunk level, X-gal staining was present in the dorsal neural tube and somites (Fig. 7A). We noted that the staining was throughout the neural plate at the tail region, and became progressively dorsally restricted in more anterior sections (Supplementary Fig. S5), suggesting that increasing $\mathrm{HH}$ levels gradually repress Gas1 expression. Consistent with this, X-gal staining was found in the

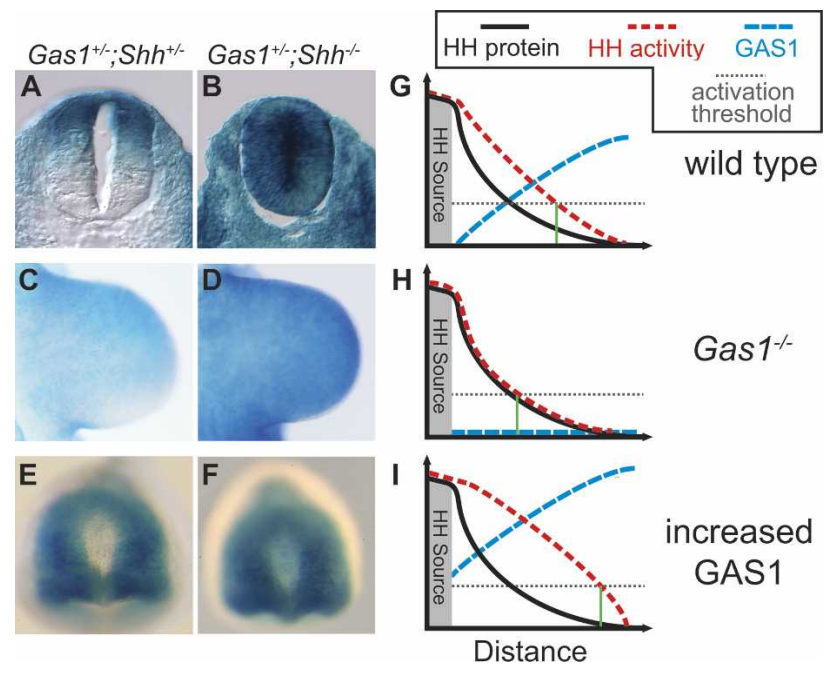

Figure 7. HH signaling negatively regulates Gas1 expression. Gas1 expression was determined by X-gal staining in E9.5 neural tubes at forelimb level $(A, B)$, E10.5 limb buds viewed dorsally $(C, D)$, and E8.0 nodes viewed ventrally $(E, F)$. Genotypes are labeled on top of each panel. $(G-I)$ Model for the role of Gas1 in transforming a hypothetical $\mathrm{HH}$ concentration gradient to an activity gradient. The $Y$-axis represents the magnitudes of three gradients: $\mathrm{HH}$ concentration (black line), $\mathrm{HH}$ activity (red dashed line), and GAS1 levels (blue dashed line). The $X$-axis represents a $\mathrm{HH}$ source and the distance from that source. The shape of the $\mathrm{HH}$ protein gradient is based in part on mathematical modeling (Saha and Schaffer 2006). GAS1 levels have direct implications for $\mathrm{HH}$ activity gradients and the distance from the $\mathrm{HH}$ source (green line) where the activation threshold (dashed gray line) for a hypothetical target gene is reached. For simplification, the contributions of other known HH-modifying proteins are not included in this model. entire neural tube and somites of $\mathrm{Gas1}^{+/-} ; \mathrm{Shh}^{-/-} \mathrm{em}$ bryos at all levels (Fig. 7B; data not shown). The presence of Gas1 in the early neural plate prior to its downregulation likely helps SHH secreted from the notochord to induce the floorplate, explaining the partial floorplate defect in the Gas1 mutant (Fig. 2V; Supplementary Fig. S2).

In the E10.5 $\mathrm{Gas1}^{+/-} ; \mathrm{Shh}^{+/-}$forelimb buds, X-gal staining was present in a gradient counter to that of high levels of $\mathrm{HH}$ signaling, but the staining in the $\mathrm{Gas1}^{+/-} ; \mathrm{Shh}^{-1-}$ embryo was throughout the entire limb bud (Fig. 7C,D). Thus, Gas1 and Ptc1 are oppositely regulated by HH signaling: Gas1 is down-regulated and Ptc1 is up-regulated. Despite this, the Gas1 and Ptc1 expression domains overlap in the middle regions of the limb bud (Lee et al. 2001a; data not shown), a location where low-level HH is known to act. We propose that at the regions where it is expressed, GAS1 exerts its activity to facilitate HH-PTC1 binding and enhance $\mathrm{HH}$ activity. The enhancement of specifically low-level HH signaling distant from the $\mathrm{HH}$ source in the limb bud is presumably due to a lack of Gas1 expression in the posterior mesenchyme even prior to ZPA formation, consistent with a lack of phenotype in the Gas1 $1^{-/-}$posterior limb. How Gas1 expression is restricted from the posterior limb bud prior to $S h$ expression is currently unknown.

The above results led us to re-examine whether Gas1 expression, regulation, and function for left/right heart asymmetry follow the same logic as for the neural tube, somite, and limb. Indeed, in E8.0 embryos, Gas1 expression inferred from X-gal staining was found in cells surrounding and posterior to the node, where $\mathrm{HH}$ signaling is crucial for specifying left-right asymmetry (Fig. 7E; Zhang et al. 2001). In the Gas1 ${ }^{+/-}$;Shh ${ }^{-/-}$embryo, X-galpositive cells were found within the node (Fig. 7F), consistent with Gas1 expression being negatively regulated by $\mathrm{HH}$ signaling. Gas1 ${ }^{-1-} ; \mathrm{Shh}^{-1-}$ embryos had a further intensified X-gal signal accompanied by a lack of detectable Ptc1 expression in the node, supporting that the left-right asymmetry defect noted in the $\mathrm{Shh}^{-/-}$; Gas1 $1^{-/-}$ embryo is due to a further reduction in $\mathrm{HH}$ signaling compared with the Shh ${ }^{-/-}$embryo (Supplementary Fig. S6). Based on the regulation of Gas1, we propose that it is a negative feedback mechanism to restrain HH signaling activity.

\section{Discussion}

We show here that Gas1 is a positive regulator of $\mathrm{HH}$ signaling in all five developmental contexts examined. Retrospectively, the microphthalmia (Lee et al. 2001b) and reduced cerebellum size (Liu et al. 2001) of the Gas1 mutant are likely also due to reduced $\mathrm{HH}$ signaling as Shh plays important roles in both contexts. The pleiotropic involvement of Gas1 in HH-directed embryonic patterning implies that it is an integral component of the HH pathway. To extend our findings, we propose that Gas1 may well be a modifier locus for the holoprosencephaly caused by reduced HH signaling and also possi- 
bly an enhancer of tumorigenesis associated with increased $\mathrm{HH}$ signaling.

GAS1's HH-binding property and its ability to enhance $\mathrm{HH}$ activity are reminiscent of the recently described CDO and BOC proteins (Tenzen et al. 2006; Zhang et al. 2006), which are homologs of Ihog and Boi, respectively, in Drosophila (Yao et al. 2006). Like Ihog (Yao et al. 2006) and CDO (this study), GAS1 can also synergize with PTC1 to bind HH. Although their expression and regulation are similar, there are differences between Gas1 and Cdo/Boc. For example, Cdo is expressed in the E9.5 notochord and floorplate, indicating that it is not regulated in the exact same manner as Gas1. Additionally, the Cdo mutant phenotype appears limited to defects in midline structures (Zhang et al. 2006) and a delay in myogenesis (Cole et al. 2004), while the Boc mutant phenotype appears limited to axon guidance (Connor et al. 2005; Okada et al. 2006). Perhaps the lack of complete loss of $\mathrm{HH}$ signaling in each single mutant is because these genes are able to partially compensate for each other in places where they are coexpressed. This possibility has been examined between Gas1 and Cdo in the accompanying study (Allen et al. 2007).

It is also possible that there is a specific context-dependent requirement for each of the genes to mediate HH signaling. The differential requirement for Gas1 versus $C d o / B o c$ in different contexts may not be surprising because $\mathrm{CDO} / \mathrm{iHog}$ and $\mathrm{BOC} / \mathrm{Boi}$ are highly related Fibronectin type III repeat-containing proteins, while GAS1 belongs to the Glial Cell-Derived Neurotrophic Factor Receptor $\alpha$ (GDNFR $\alpha$ or GFR $\alpha$ ) family (Cabrera et al. 2006). Sequence alignments between GFR $\alpha$-domaincontaining genes of various species predicted that $\mathrm{Cae}$ norhabditis elegans and honey bee genomes might have a Gas1 homolog (Schueler-Furman et al. 2006). However, the single N-glycosylation site in GAS1 required for $\mathrm{HH}$ binding is conserved among vertebrate GAS1 proteins but not found in the presumed invertebrate GAS1 proteins, suggesting that invertebrate GAS1 homologs do not function in the HH pathway. Perhaps through convergent evolution, Gas1 has acquired the ability to bind $\mathrm{HH}$ and enhance its signaling similarly to the conserved Cdo/Boc family and may be a novel addition to the $\mathrm{HH}$ signaling core pathway in vertebrates. Interestingly, GAS1 still retains the ability to modulate GDNF signaling. Given that $\mathrm{SHH}$ is involved in adult neurogenesis (Ahn and Joyner 2005) and that GDNF is a potent neuroprotective factor (Schueler-Furman et al. 2006), Gas1 may have evolved to be a nodal point for the convergence of these two important signaling pathways in the adult brain.

The observed negative regulation of Gas1 by HH signaling is in stark contrast to the positive regulation of PTC1 by HH signaling. PTC1 up-regulation has been proposed to attenuate $\mathrm{HH}$ diffusion and provides selfimposed regulation on its distance of action. Conversely, our data support a model in which HH down-regulates GAS1 to restrain its own activity. As HH concentration increases, Gas1 is correspondingly down-regulated to a level appropriate for the required magnitude of signaling amplification. This does not preclude that GAS1 can enhance local signaling. For example, the presence of GAS1 in the early neural plate prior to its down-regulation appears to be required for complete floorplate induction by SHH from the notochord. A caveat to this model is that in the posterior limb, where due to an unknown mechanism, Gas1 is not expressed prior to Shh expression in the ZPA and therefore cannot facilitate local signaling (Liu et al. 2002). Previous studies using explants of presomitic mesoderm (Lee et al. 2001a) and mandibular mesenchyme (Cobourne et al. 2004) found that overexpressed GAS1 inhibited SHH signaling. It is possible that explants cultured in vitro lost the capacity to regulate/ provide additional components necessary for GAS1 to act positively. However, a more likely explanation is that the inhibitory effects seen were due to sequestration of SHH by excessive GAS1, since under certain conditions we also observed a non-cell-autonomous inhibitory effect of GAS1 in our electroporation assay (Allen et al. 2007; data not shown). It appears that how the HH response is modulated by GAS1 is dependent on the levels of GAS1 and $\mathrm{HH}$, and possibly the cell type. Whether in vivo contexts exist where high levels of GAS1 can inhibit $\mathrm{HH}$ signaling is an intriguing possibility.

In our model, upon GAS1 gradient formation, the $\mathrm{HH}$ concentration gradient is steeper than its activity gradient, owing to the enhancement by GAS1 (Fig. 7G). When Gas1 is removed, the $\mathrm{HH}$ activity gradient becomes close to the $\mathrm{HH}$ protein gradient (Fig. $7 \mathrm{H}$ ). Conversely, when Gas1 levels are increased, the contour of the $\mathrm{HH}$ activity gradient becomes inflated (Fig. 7I). In both altered situations, shifts in the positions of the cell types being specified will occur. Thus, simultaneous up-regulation of a repressor (PTC1) and down-regulation of an enhancer of HH activity (GAS1) may not be essential for creating a signaling gradient per se, but can be instrumental to further refine multiple thresholds within the target field governed by $\mathrm{HH}$, likely part of an evolutionary process for building the increasing intricacy of vertebrate form and function.

\section{Materials and methods}

Generation of mutant Gas1 mice

See Supplementary Figure 1.

\section{Generation of embryos}

Mutant alleles of Shh (Chiang et al. 1996) and Gas1 were maintained on a mixed 129/Sv; C57BL6/J background. Noon of the vaginal plug date was considered E0.5. Genotypes were determined by PCR with yolk sac DNA using the following primers: for the Gas1 wild-type allele, 5'-TACTGCGGCAAGCTTTT CAACGG-3' and 5'-AGCGCGCTGCTCGTCGTCATATTC3'; for the Gas1 mutant allele, 5'-ACTACGCGTACTGTGA GCCAGAG-3' and 5'-AGTGACCAGCGAATACCTGTTCC3'; for the Shh wild-type allele, 5'-GACCATGTCTGCACACT TAGGTTCC-3' and 5'-GAAGGCCAGGAGGAGAAGGCTC AC-3'; for the Shh mutant allele, 5'-CGTGCAGTTCACTCA CAAGGCACT-3' and 5'-ACGAGTTCTTCTGAGGGGATC-3'. 


\section{Histology/LacZ stains}

For histology, embryos were fixed in methacarn, embedded in paraffin, sectioned at $6 \mu \mathrm{m}$, and stained by hematoxylin and eosin (Surgipath). For LacZ stains, embryos were fixed in glutaraldehyde and stained in X-gal or S-gal as described (Hogan et al. 1994).

\section{ISH}

ISH on paraffin sections $(10 \mu \mathrm{m})$ using digoxigenin-UTP (DIG)labeled antisense probes was performed for Pax1, Pax3 (Fan and Tessier-Lavigne 1994), Ptc1 (gift from M. Scott, Stanford University, Stanford, CA), and $D b x 1$. The template for $D b x 1$ probe synthesis was a PCR-amplified 2-kb mouse $D b x 1$ cDNA using the primer sequences 5'-GGTTACCAGGATACTGAGCCAAA GAG-3' and 5'-AAAATAATGAGA GGGACACAGCCAGC-3', cloned into pCR-TOPOII (Invitrogen), and transcribed by T7. Images were photographed using DIC microscopy. Wholemount ISH using DIG-labeled antisense probes was performed following standard procedures (Wilkinson 1992) for Fgf4, Gli1 (gifts from C.C. Hui, Sick Kids, University of Toronto, Toronto, Ontario, Canada), Grem (gift from R. Zeller, Utrecht University, Utrecht, The Netherlands), Shh (gift from A. McMahon, Harvard University, Cambridge, MA), and Ptc1. Images were photographed using a dissecting microscope.

\section{IHC}

SHH and IHH IHC was performed using Sainte Marie's fixative (Gritli-Linde et al. 2001). The primary antibody (Ab80) was provided by A. McMahon and used at a 1:500 dilution, followed by biotinylated goat anti-rabbit (Vector Laboratories) antibody (1:500). For other IHC, embryos were cryosectioned $(10 \mu \mathrm{m})$ following a 45-min fixation in 4\% paraformaldehyde/phosphate buffer $(\mathrm{pH} 7.2)$ at $4^{\circ} \mathrm{C}$. PAX6, PAX7, NKX6.1, NKX2.2, and HNF3 $\beta$ mouse monoclonal antibodies (DSHB) were used at a 1:10 dilution. Antibodies against DBX1 and GSH1/2 were gifts from T. Jessell (Columbia University, New York, NY) and M. Goulding (Salk Institute, La Jolla, CA), respectively. Rabbit anti-OLIG2 was purchased from Chemicon. Appropriate HRPconjugated secondary antibodies (Vector Laboratories) were used at 1:500. For visualization, DAB color development was used. Images were photographed using DIC microscopy.

\section{Skeleton preparation}

Harvested limbs were incubated in water overnight. Skin was removed following a 10 -min incubation at $65^{\circ} \mathrm{C}$, then limbs were fixed in ethanol for $5 \mathrm{~d}$ and acetone for $2 \mathrm{~d}$, and stained for $3 \mathrm{~d}$ in $67 \%$ ethanol $/ 5 \%$ glacial acetic acid $/ 23 \% \mathrm{H}_{2} \mathrm{O}$ with $0.005 \%$ (w/v) Alizarin Red S (Sigma) and $0.005 \%$ (w/v) Alcian Blue $8 \mathrm{GX}$ (Sigma). Tissue was cleared with $1 \%(\mathrm{w} / \mathrm{v}) \mathrm{KOH}$, then serially switched to increasing amounts of glycerol. Photographs were taken in $100 \%$ glycerol using a dissecting microscope.

\section{Western blots}

E10.5 limb buds were harvested and dissected into halves then lysed in $15 \mu \mathrm{L}$ of ice cold RIPA buffer plus protease inhibitors. Nuclei were removed by centrifugation, and lysates were resolved by $5 \%$ SDS-PAGE. Immunoblotting was performed using rabbit GLI-3 H-280 (Santa Cruz Biotechnology) followed by HRP-conjugated secondary antibody and ECL detection (Amer- sham). Band intensities were quantified with ImageQuant TL (Amersham Biosciences).

\section{Cell culture, conditioned media (CM), and transfection assays}

COS, 293T (ATCC), NIH3T3, and NIH3T3-GLI-Luc cells (gift from P. Beachy, Stanford University, Stanford, CA) were cultured in DMEM (high glucose) with 10\% fetal bovine serum, penicillin, and streptomycin (Invitrogen). Control and SHH-N CM were produced by $293 \mathrm{~T}$ cells transfected with $12 \mu \mathrm{g}$ of pRK5 and $12 \mu \mathrm{g}$ of pRK5-SHH-N (Fan et al. 1995), respectively, plus $30 \mu \mathrm{L}$ of Fugen $6 \mathrm{HD}$ (Roche) in a 10-cm dish. CM was collected for five consecutive days. The activities of SHH-N were determined by applying CM to NIH3T3-GLI-Luc cells for $48 \mathrm{~h}$ and assaying for luciferase activity (Promega) using D-luciferin (Sigma). Fold induction was calculated as luciferin light-emitting units from extracts of cells exposed to SHH-N CM/control $\mathrm{CM}$ after normalization to total protein. SHH-N concentrations were determined by side-by-side comparison using Western blotting and measuring the band intensity of SHH-N in the CM relative to serially diluted known amounts of bacterially produced SHH-N (BCA assay; Pierce).

For siRNA transfection assays, we used modified synthetic siRNA from Invitrogen (Stealth RNAi). Cells were transfected in 12 -well dishes at $\sim 80 \%$ confluence with $14.7 \mu \mathrm{L}$ of $20 \mu \mathrm{M}$ siRNA and $3 \mu \mathrm{L}$ of Lipofectamine 2000 (Invitrogen). For control, Stealth RNAi Negative Control Medium GC was used. For siRNA against Gas1, equal amounts of the following sequences were used: 5'-GCUGCAGAGAUAACCGGCUGAUCUA-3' and 5'-CGGCUGAUCUAUACUGCCAGCUCUA-3'. Two days after transfection, SHH-N CM was applied, and cells were harvested for luciferase assays $2 \mathrm{~d}$ later.

For shRNA assays, parental NIH3T3 cells were used. The pRNATin-H2.1/Hygro (GenScript) vector was used for expression. Of three short hairpins tested, two were effective in knocking down mGAS1 in stable lines (by hygromycin selection). Their double-stranded regions correspond to nucleotides 936-954 (in the coding region) and nucleotides 1990-2010 (in the 3' UTR) of mGas1 (NM 008,086). The results shown here are from the latter (named O3). The sequence of shRNA against YFP was as described (Yao et al. 2006). Cells in a 12-well dish were transfected using $7 \mu \mathrm{L}$ of Perfectin (Gelantis) with $1 \mu \mathrm{g}$ of pRNATin-H2.1/Hygro or pRNATin-H2.1/Hygro-O3, together with $0.25 \mu \mathrm{g}$ of a GLI-Luc reporter (Buttitta et al. 2003), $0.25 \mu \mathrm{g}$ of pSV-bgal (GIBCO), and $1 \mu \mathrm{g}$ of an effector plasmid per well. The effector plasmids are pTK (modified from pRL-TK; Promega), pTK-GPI-YFP, pTK-mGas1, pTK-hGas1, pcDNA3SmoM2, and pTK-Ptc1dl2. Ptc1dl2 was a gift from G. Struhl (Columbia University, New York, NY), and SmoM2 was from Genentech. Thirty-six hours after transfection, SHH-N or control CM was applied; $36 \mathrm{~h}$ later, cells were harvested for luciferase and $\beta$-gal (using o-nitrophenyl $\beta$-D-galactopyranoside [Sigma], followed by $\mathrm{OD}_{420 \mathrm{~nm}}$ ) assays. Fold induction was calculated as described above after normalization to $\beta$-gal activity.

For the surface binding assay, COS cells in six-well dishes were transfected with $2 \mu \mathrm{g}$ of expression vectors with $5 \mu \mathrm{L}$ of Fugen6 HD per well. pcDNA3-GPI-YFP, pcDNA3-Gas1, pcDNA3-Ptc1, pcDNA3-Smo, and pcDNA-Cdo were used. The Ptc1 cDNA was a gift from M. Scott. GPI-YFP was a gift from M. Edidin (Johns Hopkins University, Baltimore, MD). The Cdo cDNA was from an I.M.A.G.E. clone. Forty-eight hours after transfection, SHH-N-AP and control AP CM were applied. SHH-N-AP and AP CM, and ligand binding and bound AP activity measuring (using p-nitrophenyl phosphate [Sigma], fol- 
lowed by $\mathrm{OD}_{405 \mathrm{~nm}}$ ) conditions were as described (Lee et al. 2001a).

\section{Chick neural tube electroporation}

mGas1 and $m$ Gas1N/A (Lee et al. 2001a) were cloned into a pCIG-IRES-GFP vector (gift from A. McMahon) to construct pCIG-mGas1-IRES-GFP and pCIG-mGas1N/A-IRES-GFP. Hamilton and Hamberger $(\mathrm{HH})$ stage 11-12 chick embryos (SPAFAS) were injected with expression plasmids at $0.75 \mu \mathrm{g} / \mathrm{\mu L}$ into the neural tube, followed by five pulses of $30 \mathrm{~V}$ at $50 \mathrm{msec}$ per pulse with 950-msec intervals, and then incubated to stage 20-22. Embryos with visible GFP autofluorescence in the spinal cord (trunk level) were processed for immunofluorescence using the primary antibodies described above, and to GFP (Torre Pines; rabbit polyclonal, 1:1000), and followed by goat antimouse (rhodamine-conjugated, 1:500) and goat anti-rabbit (fluorescein-conjugated, 1:500) secondary antibodies. Slides were mounted in Flouromount G (Southern Biotechnology) and photographed using fluorescent microscopy.

\section{Acknowledgments}

We thank P. Beachy for the NIH3T3-GLI-Luc cells and A. McMahon for the SHH antibody. We thank Y. Zheng, L. Niswander, M. Van Doren, M. Tessier-Lavigne, C. Bargmann, and Fan Laboratory members for a critical reading of the manuscript. We thank C.E. Siple for assistance with animal genotyping and data analysis.

\section{References}

Ahn, S. and Joyner, A.L. 2004. Dynamic changes in the response of cells to positive hedgehog signaling during mouse limb patterning. Cell 118: 505-516.

Ahn, S. and Joyner, A.L. 2005. In vivo analysis of quiescent adult neural stem cells responding to Sonic hedgehog. Nature 437: 894-897.

Allen, B.L., Tenzen, T., and McMahon, A.P. 2007. The Hedgehog-binding proteins Gas1 and Cdo cooperate to positively regulate Shh signaling during mouse development. Genes \& Dev. (this issue) doi: 10.1101/gad.1543607.

Briscoe, J. and Ericson, J. 1999. The specification of neuronal identity by graded Sonic Hedgehog signalling. Semin. Cell Dev. Biol. 10: 353-362.

Briscoe, J., Sussel, L., Serup, P., Hartigan-O'Connor, D., Jessell, T.M., Rubenstein, J.L., and Ericson, J. 1999. Homeobox gene Nkx2.2 and specification of neuronal identity by graded Sonic hedgehog signalling. Nature 398: 622-627.

Briscoe, J., Chen, Y., Jessell, T.M., and Struhl, G. 2001. A hedgehog-insensitive form of patched provides evidence for direct long-range morphogen activity of sonic hedgehog in the neural tube. Mol. Cell 7: 1279-1291.

Buttitta, L., Mo, R., Hui, C.C., and Fan, C.M. 2003. Interplays of Gli2 and Gli3 and their requirement in mediating Shh-dependent sclerotome induction. Development 130: 62336243.

Cabrera, J.R., Sanchez-Pulido, L., Rojas, A.M., Valencia, A., Manes, S., Naranjo, J.R., and Mellstrom, B. 2006. Gas1 is related to the glial cell-derived neurotrophic factor family receptors $\alpha$ and regulates Ret signaling. J. Biol. Chem. 281: 14330-14339.

Casali, A. and Struhl, G. 2004. Reading the Hedgehog morphogen gradient by measuring the ratio of bound to unbound Patched protein. Nature 431: 76-80.
Chen, Y. and Struhl, G. 1996. Dual roles for Patched in sequestering and transducing Hedgehog. Cell 87: 553-563.

Chiang, C., Litingtung, Y., Lee, E., Young, K.E., Corden, J.L., Westphal, H., and Beachy, P.A. 1996. Cyclopia and defective axial patterning in mice lacking Sonic hedgehog gene function. Nature 383: 407-413.

Chiang, C., Litingtung, Y., Harris, M.P., Simandl, B.K., Li, Y., Beachy, P.A., and Fallon, J.F. 2001. Manifestation of the limb prepattern: Limb development in the absence of Sonic hedgehog function. Dev. Biol. 236: 421-435.

Cobourne, M.T., Miletich, I., and Sharpe, P.T. 2004. Restriction of Sonic hedgehog signalling during early tooth development. Development 131: 2875-2885.

Cole, F., Zhang, W., Geyra, A., Kang, J.S., and Krauss, R.S. 2004. Positive regulation of myogenic bHLH factors and skeletal muscle development by the cell surface receptor CDO. Dev. Cell 7: 843-854.

Connor, R.M., Allen, C.L., Devine, C.A., Claxton, C., and Key, B. 2005. BOC, brother of CDO, is a dorsoventral axon-guidance molecule in the embryonic vertebrate brain. J. Comp. Neurol. 485: 32-42.

Del Sal, G., Collavin, L., Ruaro, M.E., Edomi, P., Saccone, S., Valle, G.D., and Schneider, C. 1994. Structure, function, and chromosome mapping of the growth-suppressing human homologue of the murine gasl gene. Proc. Nat1. Acad. Sci. 91: 1848-1852.

Ericson, J., Muhr, J., Jessell, T.M., and Edlund, T. 1995a. Sonic hedgehog: A common signal for ventral patterning along the rostrocaudal axis of the neural tube. Int. J. Dev. Biol. 39: 809-816.

Ericson, J., Muhr, J., Placzek, M., Lints, T., Jessell, T.M., and Edlund, T. 1995b. Sonic hedgehog induces the differentiation of ventral forebrain neurons: A common signal for ventral patterning within the neural tube. Cell 81: 747-756.

Ericson, J., Morton, S., Kawakami, A., Roelink, H., and Jessell, T.M. 1996. Two critical periods of Sonic Hedgehog signaling required for the specification of motor neuron identity. Cell 87: 661-673.

Evdokiou, A. and Cowled, P.A. 1998. Growth-regulatory activity of the growth arrest-specific gene, GAS1, in NIH3T3 fibroblasts. Exp. Cell Res. 240: 359-367.

Fan, C.M. and Tessier-Lavigne, M. 1994. Patterning of mammalian somites by surface ectoderm and notochord: Evidence for sclerotome induction by a hedgehog homolog. Cell 79: $1175-1186$.

Fan, C.M., Porter, J.A., Chiang, C., Chang, D.T., Beachy, P.A., and Tessier-Lavigne, M. 1995. Long-range sclerotome induction by Sonic hedgehog: Direct role of the amino-terminal cleavage product and modulation by the cyclic AMP signaling pathway. Cell 81: 457-465.

Goodrich, L.V., Johnson, R.L., Milenkovic, L., McMahon, J.A., and Scott, M.P. 1996. Conservation of the hedgehog/patched signaling pathway from flies to mice: Induction of a mouse patched gene by Hedgehog. Genes \& Dev. 10: 301-312.

Gritli-Linde, A., Lewis, P., McMahon, A.P., and Linde, A. 2001. The whereabouts of a morphogen: Direct evidence for shortand graded long-range activity of hedgehog signaling peptides. Dev. Biol. 236: 364-386.

Harfe, B.D., Scherz, P.J., Nissim, S., Tian, H., McMahon, A.P., and Tabin, C.J. 2004. Evidence for an expansion-based temporal Shh gradient in specifying vertebrate digit identities. Cell 118: 517-528.

Hogan, B., Beddington, R., Costantini, F., and Lacey, E. 1994. Manipulating the mouse embryo, 2nd ed. Cold Spring Harbor Laboratory Press, Cold Spring Harbor, NY.

Kayed, H., Kleeff, J., Osman, T., Keleg, S., Buchler, M.W., and 
Friess, H. 2006. Hedgehog signaling in the normal and diseased pancreas. Pancreas 32: 119-129.

Kraus, P., Fraidenraich, D., and Loomis, C.A. 2001. Some distal limb structures develop in mice lacking Sonic hedgehog signaling. Mech. Dev. 100: 45-58.

Lee, C.S. and Fan, C.M. 2001. Embryonic expression patterns of the mouse and chick Gas1 genes. Mech. Dev. 101: 293-297.

Lee, C.S., Buttitta, L., and Fan, C.M. 2001a. Evidence that the WNT-inducible growth arrest-specific gene 1 encodes an antagonist of sonic hedgehog signaling in the somite. Proc. Natl. Acad. Sci. 98: 11347-11352.

Lee, C.S., May, N.R., and Fan, C.M. 2001b. Transdifferentiation of the ventral retinal pigmented epithelium to neural retina in the growth arrest specific gene 1 mutant. Dev. Biol. 236: $17-29$.

Lewis, P.M., Dunn, M.P., McMahon, J.A., Logan, M., Martin, J.F., St-Jacques, B., and McMahon, A.P. 2001. Cholesterol modification of sonic hedgehog is required for long-range signaling activity and effective modulation of signaling by Ptc1. Cell 105: 599-612.

Litingtung, Y. and Chiang, C. 2000a. Control of Shh activity and signaling in the neural tube. Dev. Dyn. 219: 143-154.

Litingtung, Y. and Chiang, C. 2000b. Specification of ventral neuron types is mediated by an antagonistic interaction between Shh and Gli3. Nat. Neurosci. 3: 979-985.

Litingtung, Y., Dahn, R.D., Li, Y., Fallon, J.F., and Chiang, C. 2002. Shh and Gli3 are dispensable for limb skeleton formation but regulate digit number and identity. Nature 418: 979-983.

Liu, Y., May, N.R., and Fan, C.M. 2001. Growth arrest specific gene 1 is a positive growth regulator for the cerebellum. Dev. Biol. 236: 30-45.

Liu, Y., Liu, C., Yamada, Y., and Fan, C.M. 2002. Growth arrest specific gene 1 acts as a region-specific mediator of the Fgf10/Fgf8 regulatory loop in the limb. Development 129: 5289-5300.

Marigo, V. and Tabin, C.J. 1996. Regulation of patched by sonic hedgehog in the developing neural tube. Proc. Natl. Acad. Sci. 93: 9346-9351.

McMahon, A.P., Ingham, P.W., and Tabin, C.J. 2003. Developmental roles and clinical significance of hedgehog signaling. Curr. Top. Dev. Biol. 53: 1-114.

Okada, A., Charron, F., Morin, S., Shin, D.S., Wong, K., Fabre, P.J., Tessier-Lavigne, M., and McConnell, S.K. 2006. Boc is a receptor for sonic hedgehog in the guidance of commissural axons. Nature 444: 369-373.

Pepinsky, R.B., Zeng, C., Wen, D., Rayhorn, P., Baker, D.P., Williams, K.P., Bixler, S.A., Ambrose, C.M., Garber, E.A., Miatkowski, K., et al. 1998. Identification of a palmitic acidmodified form of human Sonic hedgehog. J. Biol. Chem. 273: 14037-14045.

Pierani, A., Moran-Rivard, L., Sunshine, M.J., Littman, D.R., Goulding, M., and Jessell, T.M. 2001. Control of interneuron fate in the developing spinal cord by the progenitor homeodomain protein Dbx1. Neuron 29: 367-384.

Porter, J.A., Young, K.E., and Beachy, P.A. 1996. Cholesterol modification of hedgehog signaling proteins in animal development. Science 274: 255-259.

Roessler, E. and Muenke, M. 2003. How a Hedgehog might see holoprosencephaly. Hum. Mol. Genet. 12: R15-R25.

Saha, K. and Schaffer, D.V. 2006. Signal dynamics in Sonic hedgehog tissue patterning. Development 133: 889-900.

Schneider, C., King, R.M., and Philipson, L. 1988. Genes specifically expressed at growth arrest of mammalian cells. Cell 54: 787-793.

Schueler-Furman, O., Glick, E., Segovia, J., and Linial, M. 2006.
Is GAS1 a co-receptor for the GDNF family of ligands? Trends Pharmacol. Sci. 27: 72-77.

Tanabe, Y., Roelink, H., and Jessell, T.M. 1995. Induction of motor neurons by Sonic hedgehog is independent of floor plate differentiation. Curr. Biol. 5: 651-658.

Tenzen, T., Allen, B.L., Cole, F., Kang, J.S., Krauss, R.S., and McMahon, A.P. 2006. The cell surface membrane proteins Cdo and Boc are components and targets of the Hedgehog signaling pathway and feedback network in mice. Dev. Cell 10: $647-656$.

Wang, B., Fallon, J.F., and Beachy, P.A. 2000. Hedgehog-regulated processing of Gli3 produces an anterior/posterior repressor gradient in the developing vertebrate limb. Cell 100: 423-434.

Wijgerde, M., McMahon, J.A., Rule, M., and McMahon, A.P. 2002. A direct requirement for Hedgehog signaling for normal specification of all ventral progenitor domains in the presumptive mammalian spinal cord. Genes \& Dev. 16: 2849-2864.

Wilkinson, D.G. 1992. In situ hybridization: A practical approach. Oxford University Press, Oxford.

Xie, J. 2005. Hedgehog signaling in prostate cancer. Future Oncol. 1: 331-338.

Yao, S., Lum, L., and Beachy, P. 2006. The ihog cell-surface proteins bind Hedgehog and mediate pathway activation. Cell 125: 343-357.

Zeng, X., Goetz, J.A., Suber, L.M., Scott Jr., W.J., Schreiner, C.M., and Robbins, D.J. 2001. A freely diffusible form of Sonic hedgehog mediates long-range signalling. Nature 411: 716-720.

Zhang, X.M., Ramalho-Santos, M., and McMahon, A.P. 2001. Smoothened mutants reveal redundant roles for Shh and Ihh signaling including regulation of $\mathrm{L} / \mathrm{R}$ asymmetry by the mouse node. Cell 105: 781-792.

Zhang, W., Kang, J.S., Cole, F., Yi, M.J., and Krauss, R.S. 2006. Cdo functions at multiple points in the Sonic Hedgehog pathway, and Cdo-deficient mice accurately model human holoprosencephaly. Dev. Cell 10: 657-665. 


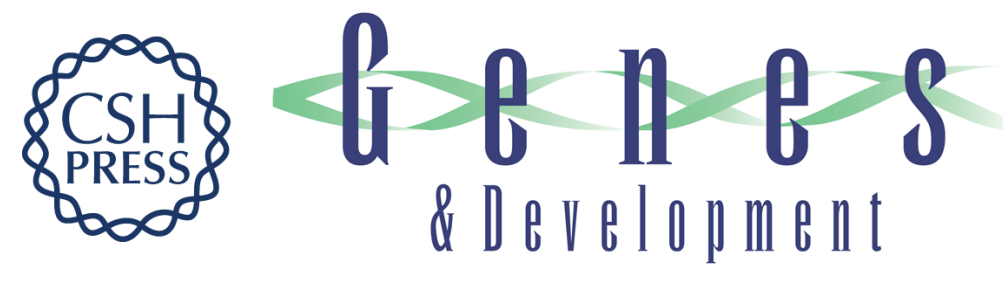

\section{Gas1 extends the range of Hedgehog action by facilitating its signaling}

David C. Martinelli and Chen-Ming Fan

Genes Dev. 2007, 21:

Access the most recent version at doi:10.1101/gad.1546307

Supplemental http://genesdev.cshlp.org/content/suppl/2007/04/30/21.10.1231.DC1
Material

References This article cites 55 articles, 12 of which can be accessed free at: http://genesdev.cshlp.org/content/21/10/1231.full.html\#ref-list-1

License

Email Alerting Receive free email alerts when new articles cite this article - sign up in the box at the top Service right corner of the article or click here.

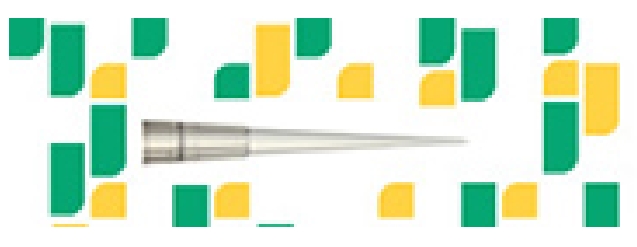

Focused on your science. 